\title{
Left ventricular filling pressure assessed by exercise TDI was correlated with early HFNEF in patients with non-obstructive hypertrophic cardiomyopathy
}

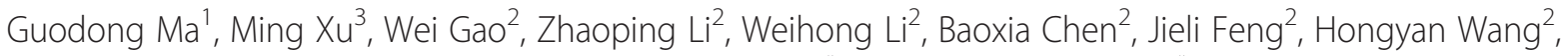
Wenying Ma ${ }^{1}$, Hui Chen ${ }^{1}$, Aidong Shen ${ }^{1}$, Xinheng Feng ${ }^{2^{*}}$ and Yongzhen Zhang ${ }^{2^{*}}$

\begin{abstract}
Background: Hypertrophic cardiomyopathy (HCM) patients are more susceptible to suffer from heart failure with normal ejection fraction (HFNEF). Therefore, it is critical to evaluate the relationship between left ventricular filling pressure (LVFP) and HFNEF, even if a large proportion of HCM patients have normal LVFP at rest. The objective was to assess the correlation between exercise tissue Doppler imaging (TDI) and early HFNEF in HCM patients by treadmill exercise echocardiography combined with cardiopulmonary exercise test (CPET).

Method: Twenty-seven non-obstructive HCM patients and 31 age- and gender-matched healthy volunteers were enrolled in this study. All subjects underwent treadmill exercise echocardiography combined with CPET. N-terminal pro-brain natriuretic peptide (NT-proBNP) levels were analyzed before and after exercise.

Result: Five HCM patients had normal LVFP at rest and increased after exercise. For this subgroup, the relationship between minute ventilation and carbon dioxide production (VENCO2 slope) and NT-proBNP levels were higher compared with controls and the subgroup with normal resting and stress LVFP, but was similar to the subgroup with elevated LVFP both at rest and after exercise.
\end{abstract}

Conclusion: Elevated LVFP after exercise suggested the occurrence of early HFNEF in patients with non-obstructive HCM.

Keywords: Tissue Doppler imaging, Heart failure with normal ejection fraction, Non-obstructive hypertrophic cardiomyopathy, Cardiopulmonary exercise testing, $\mathrm{N}$-terminal pro-brain natriuretic peptide

\section{Background}

Hypertrophic cardiomyopathy $(\mathrm{HCM})$ is characterized by left ventricular hypertrophy and is associated with a wide array of clinical symptoms and hemodynamic abnormalities, such as left ventricular outflow obstruction, diastolic dysfunction, myocardial ischemia and mitral regurgitation. The prevalence of $\mathrm{HCM}$ in the United States, Japan and China is approximately of 1 per 500 adults [1-3]. HCM is a risk factor for heart failure with normal ejection fraction (HFNEF) $[4,5]$. HFNEF has a poor prognosis because it is

\footnotetext{
*Correspondence: fengxinheng2013@126.com; zhangy_zhen@163.com ${ }^{2}$ Department of Cardiology, Peking University Third Hospital, 100191 Beijing, China

Full list of author information is available at the end of the article
}

often diagnosed and treated late $[4,5]$. Indeed, in the early diastolic dysfunction stage, a large proportion of HCM patients only suffer from impaired exercise tolerance without any other obvious symptoms or signs (such as dyspnea and edema) before the onset of clinical heart failure $[4,5]$. Therefore, there is a need to further study the diastolic dysfunction in these patients.

Elevated left ventricular filling pressure (LVFP) is critical for HFNEF diagnosis [6]. Under exercise stress, the LVFP of HFNEF patients will increase sharply because of the increase of the left ventricular preload [7-10], while this increase is not observed in adults with normal left ventricular diastolic function [11].

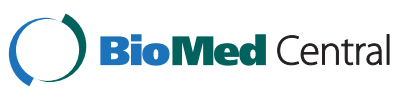

(c) 2014 Ma et al.; licensee BioMed Central. This is an Open Access article distributed under the terms of the Creative Commons Attribution License (http://creativecommons.org/licenses/by/2.0), which permits unrestricted use, distribution, and reproduction in any medium, provided the original work is properly credited. The Creative Commons Public Domain Dedication waiver (http://creativecommons.org/publicdomain/zero/1.0/) applies to the data made available in this article, unless otherwise stated. 
Tissue Doppler imaging (TDI) has been proved valuable for assessing LVFP [12-18]. The N-terminal pro-brain natriuretic peptide (NT-proBNP) is secreted by the ventricles of the heart in response to excessive stretching of the cardiomyocytes. It is therefore considered a marker of heart damage, and can be used both for screening and prognosis of heart failure $[19,20]$. NT-proBNP is usually increased in patients with left ventricular dysfunction, regardless of the presence of symptoms [21].

The aim of this study was to assess the relationship between exercise TDI and early HFNEF changes in HCM patients using treadmill exercise echocardiography combined with cardiopulmonary exercise test (CPET).

\section{Methods}

\section{Study population}

HCM patients were enrolled from those who visited the echocardiography laboratory of the Peking University Third Hospital between November 2010 and March 2011. Exclusion criteria were: 1) Patients who had a history of left ventricular outflow tract obstruction (LVOTO) diagnosis; 2) left ventricular ejection fraction (LVEF) $<50 \% ; 3$ ) atrial or ventricular arrhythmia; 4) valvular disease of moderate or greater severity; or 5) pericardial diseases.

Thirty-one age- and gender-matched healthy volunteers were enrolled as controls. The protocol was approved by Peking University Institutional Review Board. All subjects provided a written informed consent before participation.

\section{Echocardiography}

Standard 2-dimensional measurements (left ventricle diastolic and systolic dimensions, intraventricular septum (IVS), posterior wall thickness (LVPW), left atrial volume, and left ventricle outflow tract) were obtained with the patient in the supine position, before and after exercise. LV mass was calculated using the Devereux formula [22].

After obtaining the resting images from the standard parasternal and apical views, all subjects were submitted to symptoms-limited treadmill exercise (modified Bruce protocol [23]). Right after the subjects stopped exercising, echocardiography was performed in the supine position, within one minute of exercise end, using an ultrasound system (Vivid I, GE Healthcare, Waukesha, WI, USA) with a $2.5-\mathrm{MHz}$ transducer. From the apical window, a 2-mm pulsed Doppler sample volume was placed at the mitral valve tip, and mitral flow velocities of 3 cardiac cycles were recorded, obtaining peak velocities of the early diastolic transmitral flow (E), of the late diastolic transmitral flow (A), and of the early diastolic lateral mitral annulus velocity $\left(\mathrm{Em}_{\text {lateral }}\right)$ were measured by TDI using the pulsed wave Doppler mode. The filter was set to exclude high frequency signals, and the Nyquist limit was adjusted to a range of 15 to $20 \mathrm{~cm} / \mathrm{s}$. Gain and sample volume were minimized to allow for a clear tissue signal with minimal

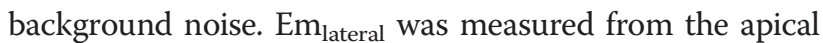
4-chamber view with a $2 \mathrm{~mm}$ sample volume placed at the lateral corner of the mitral annulus. These measurements were made at baseline and during recovery, in the same sequence. Measurements were recorded with simultaneous electrocardiography. All data were digitally stored.

\section{Cardiopulmonary exercise testing}

Each subject was submitted to a symptoms-limited modified Bruce protocol [23] treadmill CPET under the supervision of a qualified exercise physiologist and a physician. Expired gases were collected continuously throughout exercise and analyzed for ventilatory volume (VE), and for oxygen $\left(\mathrm{O}_{2}\right)$ and carbon dioxide $\left(\mathrm{CO}_{2}\right)$ content by a professional analyzer. Expired gases were reported every $30 \mathrm{sec}-$ onds, and were reported as peak oxygen consumption $\left(\mathrm{VO}_{2 \mathrm{max}}, \mathrm{ml} / \mathrm{kg} / \mathrm{min}\right)$, peak respiratory exchange ratio (the ratio of $\mathrm{CO}_{2}$ production to $\mathrm{O}_{2}$ consumption at peak effort), and $\mathrm{VE} / \mathrm{VCO}_{2}$ slope (the slope of the increase in peak ventilation/increase in $\mathrm{CO}_{2}$ production throughout exercise).

Heart monitoring consisted of continuous 12-lead electrocardiography, automatic blood pressure measurements, and heart rate (HR) recordings at every stage via the electrocardiogram. Test termination criteria were: 1) patient's request; 2) ventricular tachycardia; 3) $2 \mathrm{~mm}$ or more of horizontal or down sloping ST-segment depression; or 4) a drop in systolic blood pressure (SBP) of $20 \mathrm{~mm} \mathrm{Hg}$ or more.

\section{NT-proBNP measurement}

Blood samples for analysis of NTproBNP were obtained before the start of exercise and at maximal exercise. Serum NT-proBNP levels were determined using an electro-chemiluminescence immunoassay according to the manufacturer's instructions performed on a Cobas E601 (Roche Diagnostics, Basel, Switzerland).

\section{Statistical analysis}

Normally distributed continuous variables are expressed as means $\pm \mathrm{SD}$. Non-normally distributed continuous variables were log-transformed to normalize their distribution for analysis. Categorical data are expressed as percentages. Variables between the study groups were compared by the Student's t-test and by one-way analysis of variance (ANOVA). Non-parametric tests were used in cases of unequal variances. Variables at rest and peak stress within each group were compared by the Student's t-test and categorical data were compared by the pearsonchi-square test. Differences were considered significant when the $\mathrm{p}$-value was $<0.05$. All analyses were performed using SPSS 17.0 (SPSS Inc., Chicago, IL, USA). 


\section{Results}

Patients' characteristics

Two hundred and sixty-eight patients were screened; 103 patients suffered from atrial fibrillation, 43 refused to participate, 39 patients could not be contacted, 12 patients suffered from left ventricular outflow tract obstruction, 35 suffered from severe mitral valve regurgitation, 5 had a hydropericardium, and 4 patients had limited physical capacities. Therefore, 27 patients were included. The clinical characteristics of HCM patients and controls are compared in Table 1 . There were no differences in age, gender, body mass index (BMI), and comorbidities (hypertension and diabetes).

Hemodynamic and echocardiographic parameters are compared in Table 2. There were no statistical differences in resting and stress $\operatorname{HR}(\mathrm{p}=0.621$ and 0.086 , resepectively) and $\operatorname{SBP}(\mathrm{p}=0.955$ and 0.615 , respectively) between the two groups. Standard echocardiography showed that there were no differences in LVEF, LVESD and LVEDD (all P>0.05). However, the HCM patients displayed larger LAD, LAA, IVS, LVPW and LVMI (all p < 0.01) (Table 2).

\section{Doppler mitral inflow}

The baseline peak velocity of $\mathrm{E}$ in the HCM group was lower than in controls $(0.61 \pm 0.16$ vs. $0.72 \pm 0.15, \mathrm{P}<0.05)$. There were no differences in other mitral inflow variables between the two groups.

\section{TDI parameters}

Both baseline and stress $\mathrm{Em}_{\text {lateral }}$ of the HCM group were lower than in controls (baseline: $8.1 \pm 2.6$ vs. $11.3 \pm$ $2.3, \mathrm{p}<0.001 ; 10.3 \pm 3.2$ vs. $13.3 \pm 2.8 \mathrm{p}<0.01)$. There was no difference in baseline $\mathrm{Sm}_{\text {lateral }}$ between the two groups (baseline: $9.1 \pm 2.3$ vs. $9.7 \pm 2.0, p>0.05$ ). But stress $\mathrm{Sm}_{\text {lateral }}$ of the HCM group were lower than in controls $(14.3 \pm 4.1$ vs. $16.3 \pm 3.0 \mathrm{p}<0.05)$ (Table 2). Both baseline and exercise $\mathrm{E} / \mathrm{Em}_{\text {lateral }}$ were higher in $\mathrm{HCM}$ patients (baseline: $8.0 \pm 2.5$ vs. $6.5 \pm 1.5, \mathrm{P}<0.01$; exercise: $9.1 \pm 3.0$ vs. $7.1 \pm 1.3, \mathrm{P}<0.01)$. E/Em lateral increased after exercise in HCM patients (from $8.0 \pm 2.5$ to $9.1 \pm 3.0$, $\mathrm{P}<0.01$ ), but not in controls (from $6.5 \pm 1.5$ to $7.1 \pm 1.3$, $\mathrm{P}=0.085$ ) (Table 3).

Table 1 Clinical characteristics

\begin{tabular}{lccc}
\hline Characteristics & HCM $(\mathbf{n}=\mathbf{2 7})$ & Control $(\mathbf{n}=\mathbf{3 1})$ & $\mathbf{p}$-value \\
\hline Age (mean, yrs) & $54.3 \pm 12.4$ & $49.3 \pm 6.4$ & 0.075 \\
Female gender $(\mathrm{n}, \%)$ & $11(42.3)$ & $16(51.6)$ & 0.483 \\
Body mass index $\left(\mathrm{kg} / \mathrm{m}^{2}\right)$ & $25.9 \pm 4.6$ & $24.6 \pm 4.3$ & 0.224 \\
Hypertension $(\mathrm{n}, \%)$ & $10(38.5)$ & $7(22.6)$ & 0.192 \\
Diabetes $(\mathrm{n}, \%)$ & $2(7.9)$ & $1(9.7)$ & 0.875 \\
\hline
\end{tabular}

Table 2 Hemodynamic and echocardiographic parameters

\begin{tabular}{|c|c|c|c|}
\hline Variable & HCM $(n=27)$ & Control $(n=31)$ & P-value \\
\hline Resting HR (beats/min) & $70 \pm 10$ & $69 \pm 11$ & 0.621 \\
\hline Stress HR (beats/min) & $110 \pm 19$ & $118 \pm 16$ & 0.086 \\
\hline Resting SBP (mmHg) & $123 \pm 13$ & $124 \pm 19$ & 0.955 \\
\hline Stress SBP (mmHg) & $160 \pm 25$ & $156 \pm 30$ & 0.615 \\
\hline $\mathrm{LAD}(\mathrm{mm})$ & $34.4 \pm 4.8$ & $31.3 \pm 3.9$ & $<0.01$ \\
\hline LAA $\left(\mathrm{cm}^{2}\right)$ & $18.6 \pm 3.6$ & $16.0 \pm 2.8$ & $<0.01$ \\
\hline IVS (mm) & $15.6 \pm 4.0$ & $8.6 \pm 1.3$ & $<0.001$ \\
\hline LVPW (mm) & $9.7 \pm 2.2$ & $8.3 \pm 1.2$ & $<0.01$ \\
\hline LVEDD (mm) & $43.7 \pm 5.9$ & $44.5 \pm 6.2$ & 0.644 \\
\hline $\operatorname{LVESD}(\mathrm{mm})$ & $25.8 \pm 5.5$ & $27.0 \pm 4.9$ & 0.407 \\
\hline LVEF (\%) & $71.3 \pm 8.8$ & $69.4 \pm 6.2$ & 0.340 \\
\hline LVMI $\left(\mathrm{g} / \mathrm{m}^{2}\right)$ & $126.5 \pm 31.7$ & $78.3 \pm 21.7$ & $<0.001$ \\
\hline Baseline $E(m / s)$ & $0.61 \pm 0.16$ & $0.72 \pm 0.15$ & $<0.05$ \\
\hline Stress E (m/s) & $0.88 \pm 0.20$ & $0.93 \pm 0.20$ & 0.356 \\
\hline Baseline A (m/s) & $0.68 \pm 0.13$ & $0.70 \pm 0.13$ & 0.581 \\
\hline Stress A (m/s) & $0.99 \pm 0.20$ & $1.04 \pm 0.22$ & 0.318 \\
\hline Baseline E/A & $0.92 \pm 0.29$ & $1.06 \pm 0.29$ & 0.070 \\
\hline Stress E/A & $0.90 \pm 0.17$ & $0.91 \pm 0.22$ & 0.840 \\
\hline Baseline $\mathrm{Sm}_{\text {lateral }}$ & $9.1 \pm 2.3$ & $9.7 \pm 2.0$ & 0.262 \\
\hline Stress $\mathrm{Sm}_{\text {lateral }}$ & $14.3 \pm 4.1$ & $16.3 \pm 3.0$ & $<0.05$ \\
\hline Baseline Em lateral & $8.1 \pm 2.6$ & $11.3 \pm 2.3$ & $<0.001$ \\
\hline Stress Emlateral & $10.3 \pm 3.2$ & $13.3 \pm 2.8$ & $<0.001$ \\
\hline
\end{tabular}

HR: heart rate; SBP: systolic blood pressure; LAD: left anterior descending artery; LAA: left atrial appendage; IVS: intraventricular septum; LVPW: posterior wall of the left ventricle; LVEDD: left ventricular end-diastolic dimension; LVESD: left ventricular end-systolic dimension; LVEF: left ventricle ejection fraction; LVMI: left ventricular mass index; E: early diastolic transmitral flow; A: late diastolic transmitral flow; Em lateral: early diastolic lateral mitral annulus velocity.

\section{CPET parameters}

For $\mathrm{HCM}$ patients, $\mathrm{VO}_{2 \max }$ was lower $(24.3 \pm 5.2$ vs. $27.6 \pm$ $3.9, \mathrm{P}<0.01)$ and $\mathrm{VE} / \mathrm{VCO}_{2}$ slope was higher $(28.8 \pm 4.0$ vs. $26.9 \pm 2.7, \mathrm{P}<0.05$ ) than in controls (Table 4 ). No LVOTO was observed in the HCM patients after CPET.

\section{NT-proBNP}

In HCM patients, both baseline and exercise NT-proBNP were higher than in controls (baseline: $884 \mathrm{vs} .72 \mathrm{pg} / \mathrm{ml}$, $\mathrm{P}<0.001$; exercise: 1019 vs. 79 pg/ml, $\mathrm{P}<0.001$ ) (Table 4).

Table 3 Baseline and stress $\mathrm{E} / \mathrm{Em}_{\text {lateral }}$

\begin{tabular}{lccc}
\hline Variable & HCM $(\mathbf{n}=\mathbf{2 7})$ & Control $(\mathbf{n}=\mathbf{3 1})$ & P-value \\
\hline Baseline E/Em & $8.0 \pm 2.5$ & $6.5 \pm 1.5$ & $<0.01$ \\
Stress E/Em & & $7.1 \pm 1.3$ & $<0.01$ \\
P-valueral & $9.1 \pm 3.0$ & 0.085 & \\
\hline
\end{tabular}

E: early diastolic transmitral flow; Em lateral: early diastolic lateral mitral annulus velocity. 
Table 4 CPET parameters and NT-proBNP

\begin{tabular}{lccc}
\hline Variable & HCM $(\mathbf{n}=\mathbf{2 7})$ & Control $(\mathbf{n}=\mathbf{3 1})$ & P-value \\
\hline $\mathrm{VO}_{2}$ max $(\mathrm{ml} / \mathrm{min} . \mathrm{kg})$ & $24.3 \pm 5.2$ & $27.6 \pm 3.9$ & $<0.01$ \\
$\mathrm{VENCO}_{2}$ Slope & $28.8 \pm 4.0$ & $26.9 \pm 2.7$ & $<0.05$ \\
Baseline NT-proBNP $(\mathrm{pg} / \mathrm{ml})$ & 884 & 72 & $<0.001$ \\
Stress NT-proBNP $(\mathrm{pg} / \mathrm{ml})$ & 1019 & 79 & $<0.001$ \\
\hline
\end{tabular}

VO2max: maximal oxygen consumption; VE/VCO2 slope: relationship between minute ventilation and carbon dioxide production; NT-proBNP: N-terminal pro-brain natriuretic peptide.

\section{Subgroups comparisons}

According to an E/Em lateral above or below 10 before and after exercise, the HCM group could be divided into 3 subgroups: group A $(\mathrm{n}=17$, baseline and stress $\left.\mathrm{E} / \mathrm{Em}_{\text {lateral }}<10\right)$, group $\mathrm{B}\left(\mathrm{n}=5\right.$, baseline $\mathrm{E} / \mathrm{Em}_{\text {lateral }}<10$, and stress $\left.E / \mathrm{Em}_{\text {lateral }}>10\right)$, and group $C(n=5$, baseline and stress $E / \mathrm{Em}_{\text {lateral }}>10$ ) (Table 5 ). In group $\mathrm{B}$, the $\mathrm{E} / \mathrm{Em}_{\text {lateral }}$ ratio was increased in all patients $(\mathrm{P}<0.05)$ (Figure 1). There were no differences in age, BMI, LVEDD, LVESD and LVEF between the controls and the three $\mathrm{HCM}$ subgroups. The $\mathrm{VE} / \mathrm{VCO}_{2}$ slope in group $\mathrm{B}$ was similar to that of group $\mathrm{C}(\mathrm{p}>0.05)$, but was higher compared with group A $(\mathrm{p}<0.05)$ and controls $(\mathrm{p}<0.05)$ (Figure 2). NT-proBNP in group B was similar to that of group $C(p>0.05)$, but was higher compared with group A $(\mathrm{p}<0.05)$ and controls $(\mathrm{p}<0.01)$ (Figures 3 and 4$)$.

\section{Discussion}

The main goal of this study was to assess the value of exercise TDI in early HFNEF detection in HCM patients by treadmill exercise echocardiography combined with CPET. These preliminary results showed that the higher $\mathrm{E} / \mathrm{Em}$, the worse the outcomes. E/Em may rise in a minority of patients following exercise, in whom it was normal at rest. This may indicate a rise in filling pressure during exertion and mild HFNEF. In addition, differences in stress E/Em appears to be mainly driven by the lower Em since mitral $\mathrm{E}$ wave peak velocity was not different between the groups.

Impaired exercise tolerance is the most common symptom in HCM patients [24]. Because diastolic dysfunction reduces the filling of the left ventricle, the heart cannot pump enough blood to satisfy the needs of the body when exercising, thus causing damage to the heart due to exercise intolerance and raised LVFP [25,26]. However, it is also possible that the cause of exercise intolerance might be secondary to the inability of the stroke volume to increase appropriately because of abnormal sarcomeric protein causing abnormal contractility and reduced inotropic reserve [26,27]. We observed that HCM patients had higher E/Em, VE/VCO2 slope and lower VO2max. Past studies revealed that VO2max was correlated with prognosis in heart failure patients [28]. In the present study, impaired VO2max in HCM patients may be an indicator of their bad prognosis.

Moreover, during CPET, some individuals could not reach the anaerobic threshold for some reasons. In this condition, VO2max cannot reflect the actual exercise tolerance and diastolic function. It has also been found that the VE/VCO2 slope, which was negatively correlated with prognosis, was a better indicator of prognosis in heart failure patients than $\mathrm{VO} 2 \mathrm{max}$, without consideration of reaching the anaerobic threshold or not [16,29-33]. In the present study, HCM patients had higher VE/VCO2 slope than controls, suggesting that HCM patients may have worse outcomes and need to be treated earlier.

Table 5 Parameters of the control and 3 HCM subgroups

\begin{tabular}{|c|c|c|c|c|c|}
\hline Variable & Control $(n=31)$ & Subgroup A ( $n=17)$ & Subgroup B $(n=5)$ & Subgroup $C(n=5)$ & P-value \\
\hline Age (yrs) & $49.3 \pm 6.4$ & $51.1 \pm 11.1$ & $52.4 \pm 12.6$ & $66.4 \pm 10.7$ & $>0.05$ \\
\hline $\mathrm{BMI}\left(\mathrm{Kg} / \mathrm{m}^{2}\right)$ & $24.6 \pm 3.3$ & $25.4 \pm 4.5$ & $25.4 \pm 5.4$ & $27.9 \pm 4.7$ & 0.391 \\
\hline LVMI $\left(\mathrm{g} / \mathrm{m}^{2}\right)$ & $78.3 \pm 21.7$ & $120.1 \pm 26.6$ & $145.2 \pm 51.3$ & $127.4 \pm 20.0$ & $>0.05^{*}$ \\
\hline LVEDD (mm) & $43.7 \pm 5.9$ & $42.7 \pm 6.1$ & $43.0 \pm 6.9$ & $48.0 \pm 2.4$ & 0.424 \\
\hline $\operatorname{LVESD}(\mathrm{mm})$ & $25.8 \pm 5.5$ & $24.9 \pm 5.2$ & $24.4 \pm 5.8$ & $30.2 \pm 4.6$ & 0.152 \\
\hline LVEF (\%) & $69 \pm 6$ & $72 \pm 9$ & $74 \pm 7$ & $65 \pm 9$ & 0.169 \\
\hline Baseline E/Em lateral & $6.5 \pm 1.5$ & $6.8 \pm 1.4$ & $8.0 \pm 2.5$ & $11.8 \pm 1.2$ & $<0.001$ \\
\hline Stress $E / E_{\text {lateral }}$ & $7.1 \pm 1.3$ & $7.3 \pm 1.3$ & $10.5 \pm 0.4$ & $14.0 \pm 2.8$ & $<0.001$ \\
\hline $\mathrm{VO}_{2} \max (\mathrm{ml} / \mathrm{Kg})$ & $27.7 \pm 3.9$ & $24.7 \pm 5.0$ & $24.8 \pm 6.3$ & $22.3 \pm 5.1$ & $<0.05$ \\
\hline VENCO 2 slope & $26.9 \pm 2.7$ & $27.4 \pm 4.2$ & $30.7 \pm 1.9$ & $31.3 \pm 2.6$ & $<0.01$ \\
\hline Baseline LnNTproBNP & $3.9 \pm 0.8$ & $5.5 \pm 1.4$ & $7.4 \pm 0.8$ & $6.7 \pm 0.6$ & $<0.01$ \\
\hline Stress LnNTproBNP & $4.0 \pm 0.8$ & $5.6 \pm 1.4$ & $7.5 \pm 0.7$ & $6.9 \pm 0.6$ & $<0.01$ \\
\hline
\end{tabular}

*groups $\mathrm{A}, \mathrm{B}$ and $\mathrm{C}$ were not different, all above the control.

BMI: body mass index; LVMI: left ventricular mass index; LVEDD: left ventricular end-diastolic dimension; LVESD: left ventricular end-systolic dimension; LVEF: left ventricle ejection fraction; VO2max: maximal oxygen consumption; VE/VCO2 slope: relationship between minute ventilation and carbon dioxide production; NT-proBNP: N-terminal pro-brain natriuretic peptide; E: early diastolic transmitral flow; Emlateral: early diastolic lateral mitral annulus velocity. 


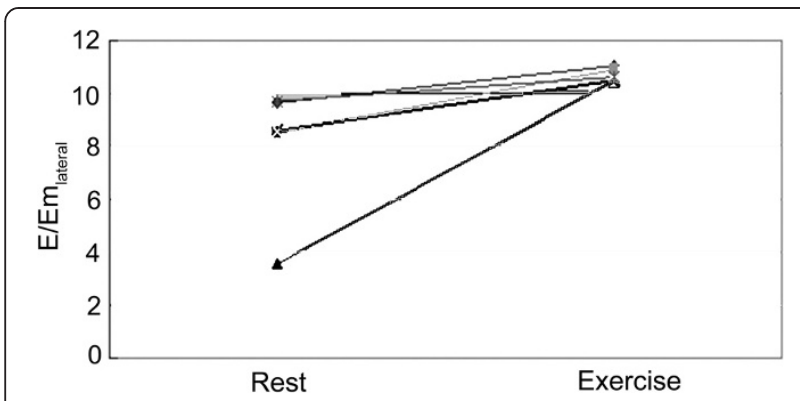

Figure 1 Changes in $\mathrm{E} / \mathrm{Em}_{\text {lateral }}$ after exercising in all subjects.

We observed that the LVFP of about $20 \%$ of our HCM patients was significantly higher immediately after exercise (baseline $\mathrm{E} / \mathrm{Em}<10$ and stress $\mathrm{E} / \mathrm{Em}>10$, group $\mathrm{b}$ ), and that these patients may be diagnosed as early or latent HFNEF. As previously mentioned, the VE/VCO2 slope and NT-proBNP levels are negatively correlated with prognosis [16,19-21,29-33]. These two prognostic indexes were similar between groups $B$ (i.e. latent HFNEF group) and $C$ (i.e. clinical HFNEF), but were higher than in group $\mathrm{A}$, suggesting unfavorable outcomes of early HFNEF in HCM patients. Thus, early HFNEF in HCM patients might require a particular medical attention.

Our results are supported by some previously published studies. Kitaoka et al. [34] showed that TDI after CPET was more useful than BNP levels for predicting objective capacity in HCM patients. However, they did not assess HFNEF onset. Another study by the same author showed that a high septal ratio and elevated BNP levels discriminated HCM patients who suffered from a cardiac event vs. those who did not [35]. Finally, a study suggested that TDI was useful for risk stratification of HCM patients, but BNP levels were not assessed [36].

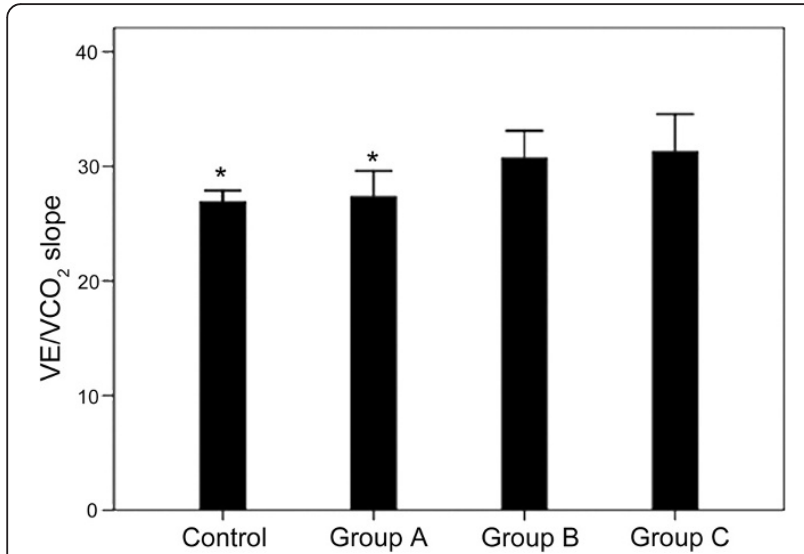

Figure 2 Comparison of VE/VCO2 between the four groups. Group A: baseline E/Em $<10$ and stress E/Em $<10(n=17)$. Group B: baseline $E / E m<10$ and stress E/Em $>10(n=5)$. Group B: baseline E/Em $>10$ and stress E/Em $>10(n=5)$. Controls $(n=31)$. ${ }^{P} P<0.05$ vs. group B.

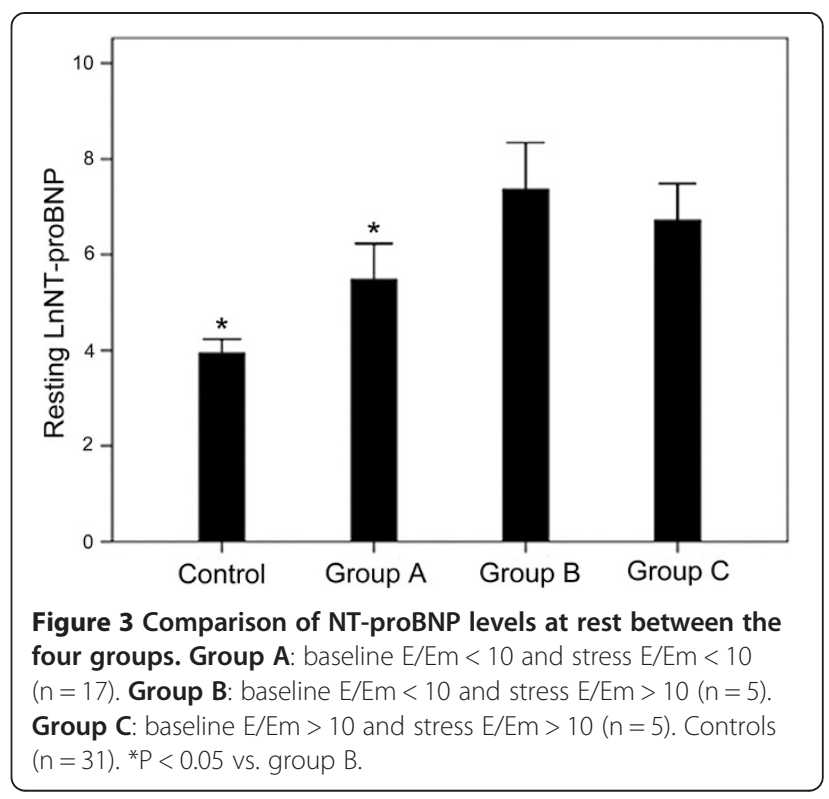

Em measurement might have been affected by sample size, gain, filter and minimal angulation with annular motion. We selected the lateral mitral annulus, because it is easy to obtain measurements from this site from the apical window. We had experienced technician to ensure the reproducibility and to minimize the variability. Em was reduced in patients with annular calcification and mitral stenosis, and was increased in patients with moderate to severe mitral regurgitation. Therefore, these patients were not included in our study. In addition, E velocity could decrease rapidly after exercise; therefore, we measured $\mathrm{E}$ velocity within one minute after exercise termination. Because of the relatively small number of enrolled

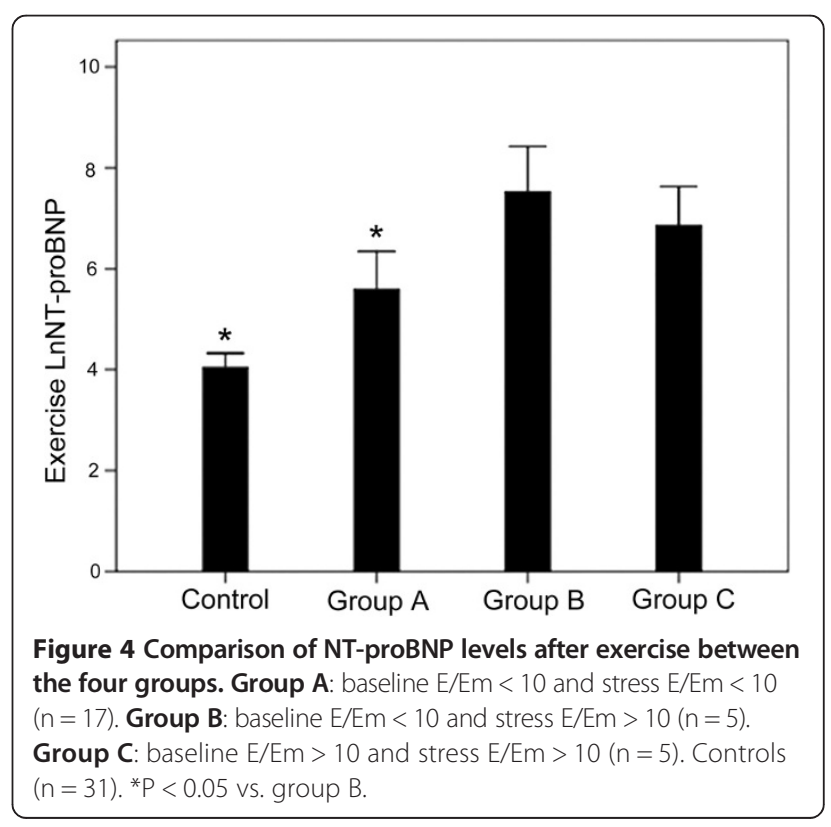


patients, larger studies are needed to prove the value of exercise TDI in diagnosis of HFNEF in HCM patients. However, the use of control patients enhances the reliability of our study.

\section{Conclusions}

In conclusion, the results suggest that the LVFP of HCM patients was higher than healthy adults and that exercise TDI have a potential value for early HFNEF diagnosis in HCM patients.

\section{Competing interests}

The authors declare that they have no competing interests.

\section{Authors' contributions}

GM, MX, WG, ZL, WL, BC, JF, HW and WM participated in data collection, data analysis, preparation of manuscript. GM, HC, AS and YZ participated in data collection, literature analysis and search. GM and XF conceived of the study and participated in the design and coordination. All authors read and approved the final manuscript.

\section{Acknowledgements}

This study was supported by the National High Technology Research and Development Program of China (Grant No. 2007AA02Z457).

\section{Author details}

'Department of Cardiology, Beijing Friendship Hospital, Capital Medical University, 100050 Beijing, China. ${ }^{2}$ Department of Cardiology, Peking University Third Hospital, 100191 Beijing, China. ${ }^{3}$ Key Laboratory of Cardiovascular Molecular Biology and Regulatory Peptides, Ministry of Health, 100191 Beijing, China.

Received: 21 January 2014 Accepted: 23 June 2014

Published: 18 December 2014

\section{References}

1. Ommen SR, Nishimura RA: Hypertrophic cardiomyopathy. Curr Probl Cardiol 2004, 29:239-291

2. Wigle ED, Rakowski H, Kimball BP, Williams WG: Hypertrophic cardiomyopathy: clinical spectrum and treatment. Circulation 1995, 92:1680-1692

3. Zou Y, Song L, Wang Z, Ma A, Liu T, Gu H, Lu S, Wu P, Zhang Dagger Y, Shen dagger $L$, Cai Y, Zhen double dagger Y, Liu Y, Hui R: Prevalence of idiopathic hypertrophic cardiomyopathy in China: a population-based echocardiographic analysis of 8080 adults. Am J Med 2004, 116:14-18.

4. Owan TE, Hodge DO, Herges RM, Jacobsen SJ, Roger VL, Redfield MM: Trends in prevalence and outcome of heart failure with preserved ejection fraction. N Engl J Med 2006, 355:251-259.

5. Abhayaratna WP, Marwick TH, Smith WT, Becker NG: Characteristics of left ventricular diastolic dysfunction in the community: an echocardiographic survey. Heart 2006, 92:1259-1264.

6. Brutsaert DL, Sys SU, Gillebert TC: Diastolic failure: pathophysiology and therapeutic implications. J Am Coll Cardiol 1993, 22:318-325.

7. Westermann D, Kasner M, Steendijk P, Spillmann F, Riad A, Weitmann K, Hoffmann W, Poller W, Pauschinger M, Schultheiss HP, Tschope C: Role of left ventricular stiffness in heart failure with normal ejection fraction. Circulation 2008, 117:2051-2060.

8. Borlaug BA, Nishimura RA, Sorajja P, Lam CS, Redfield MM: Exercise hemodynamics enhance diagnosis of early heart failure with preserved ejection fraction. Circ Heart Fail 2010, 3:588-595.

9. Kawaguchi M, Hay I, Fetics B, Kass DA: Combined ventricular systolic and arterial stiffening in patients with heart failure and preserved ejection fraction: implications for systolic and diastolic reserve limitations. Circulation 2003, 107:714-720.

10. Borlaug BA, Jaber WA, Ommen SR, Lam CS, Redfield MM, Nishimura RA: Diastolic relaxation and compliance reserve during dynamic exercise in heart failure with preserved ejection fraction. Heart 2011, 97:964-969.
11. Cheng $C P$, Igarashi $Y$, Little WC: Mechanism of augmented rate of left ventricular filling during exercise. Circ Res 1992, 70:9-19.

12. Nagueh SF, Middleton KJ, Kopelen HA, Zoghbi WA, Quinones MA: Doppler tissue imaging: a noninvasive technique for evaluation of left ventricular relaxation and estimation of filling pressures. J Am Coll Cardiol 1997, 30:1527-1533.

13. Burgess Ml, Jenkins C, Sharman JE, Marwick TH: Diastolic stress echocardiography: hemodynamic validation and clinical significance of estimation of ventricular filling pressure with exercise. J Am Coll Cardiol 2006, 47:1891-1900.

14. Talreja DR, Nishimura RA, Oh JK: Estimation of left ventricular filling pressure with exercise by Doppler echocardiography in patients with normal systolic function: a simultaneous echocardiographic-cardiac catheterization study. J Am Soc Echocardiogr 2007, 20:477-479.

15. Ha JW, Lulic F, Bailey KR, Pellikka PA, Seward JB, Tajik AJ, Oh JK: Effects of treadmill exercise on mitral inflow and annular velocities in healthy adults. Am J Cardio/ 2003, 91:114-115.

16. Guazzi M, Dickstein K, Vicenzi M, Arena R: Six-minute walk test and cardiopulmonary exercise testing in patients with chronic heart failure: a comparative analysis on clinical and prognostic insights. Circ Heart Fail 2009, 2:549-555.

17. Nagueh SF, Lakkis NM, Middleton KJ, Spencer WH III, Zoghbi WA, Quinones MA: Doppler estimation of left ventricular filling pressures in patients with hypertrophic cardiomyopathy. Circulation 1999, 99:254-261.

18. Geske JB, Sorajja P, Nishimura RA, Ommen SR: Evaluation of left ventricular filling pressures by Doppler echocardiography in patients with hypertrophic cardiomyopathy: correlation with direct left atrial pressure measurement at cardiac catheterization. Circulation 2007, 116:2702-2708.

19. Maisel AS, Krishnaswamy P, Nowak RM, McCord J, Hollander JE, Duc P, Omland T, Storrow AB, Abraham WT, Wu AH, Clopton P, Steg PG, Westheim A, Knudsen CW, Perez A, Kazanegra R, Hermann HC, McCullough PA: Rapid measurement of B-type natriuretic peptide in the emergency diagnosis of heart failure. N Engl J Med 2002, 347:161-167.

20. Bhalla V, Willis S, Maisel AS: B-type natriuretic peptide: the level and the drug-partners in the diagnosis of congestive heart failure. Congest Heart Fail 2004, 10:3-27.

21. Atisha D, Bhalla MA, Morrison LK, Felicio L, Clopton P, Gardetto N, Kazanegra $R$, Chiu A, Maisel AS: A prospective study in search of an optimal B-natriuretic peptide level to screen patients for cardiac dysfunction. Am Heart J 2004, 148:518-523.

22. Devereux RB, Reichek N: Echocardiographic determination of left ventricular mass in man: anatomic validation of the method. Circulation 1977, 55:613-618.

23. Sullivan M, McKirnan MD: Errors in predicting functional capacity for postmyocardial infarction patients using a modified Bruce protocol. Am Heart J 1984, 107:486-492.

24. Maron BJ: Hypertrophic cardiomyopathy. Lancet 1997, 350:127-133.

25. Briguori C, Betocchi S, Romano M, Manganelli F, Angela Losi M, Ciampi Q, Gottilla R, Lombardi R, Condorelli M, Chiariello M: Exercise capacity in hypertrophic cardiomyopathy depends on left ventricular diastolic function. Am J Cardiol 1999, 84:309-315.

26. Lele SS, Thomson HL, Seo H, Belenkie I, McKenna WJ, Frenneaux MP Exercise capacity in hypertrophic cardiomyopathy: role of stroke volume limitation, heart rate, and diastolic filling characteristics. Circulation 1995, 92:2886-2894

27. Critoph $\mathrm{CH}$, Patel V, Mist B, Elliott PM: Cardiac output response and peripheral oxygen extraction during exercise among symptomatic hypertrophic cardiomyopathy patients with and without left ventricular outflow tract obstruction. Heart 2014, 100:639-646.

28. Cohen-Solal A, Tabet JY, Logeart D, Bourgoin P, Tokmakova M, Dahan M: A non-invasively determined surrogate of cardiac power ('circulatory power') at peak exercise is a powerful prognostic factor in chronic heart failure. Eur Heart J 2002, 23:806-814.

29. Bard RL, Gillespie BW, Clarke NS, Egan TG, Nicklas JM: Determining the best ventilatory efficiency measure to predict mortality in patients with heart failure. J Heart Lung Transplant 2006, 25:589-595.

30. Arena R, Myers J, Aslam SS, Varughese EB, Peberdy MA: Peak VO2 and VE/VCO2 slope in patients with heart failure: a prognostic comparison. Am Heart J 2004, 147:354-360.

31. Cicoira M, Davos CH, Florea V, Shamim W, Doehner W, Coats AJ, Anker SD: Chronic heart failure in the very elderly: clinical status, survival, and 
prognostic factors in 188 patients more than 70 years old. Am Heart $J$ 2001, 142:174-180.

32. Arena R, Myers J, Abella J, Peberdy MA, Bensimhon D, Chase P, Guazzi M: Development of a ventilatory classification system in patients with heart failure. Circulation 2007, 115:2410-2417.

33. Arena RA, Guazzi M, Myers J, Abella J: The prognostic value of ventilatory efficiency with beta-blocker therapy in heart failure. Med Sci Sports Exerc 2007, 39:213-219.

34. Kitaoka H, Kubo T, Okawa M, Hirota T, Hayato K, Yamasaki N, Matsumura Y, Doi YL: Utility of tissue Doppler imaging to predict exercise capacity in hypertrophic cardiomyopathy: comparison with B-type natriuretic peptide. J Cardiol 2009, 53:361-367.

35. Kitaoka H, Kubo T, Okawa M, Takenaka N, Sakamoto C, Baba Y, Hayashi K, Yamasaki N, Matsumura Y, Doi YL: Tissue doppler imaging and plasma BNP levels to assess the prognosis in patients with hypertrophic cardiomyopathy. J Am Soc Echocardiogr 2011, 24:1020-1025.

36. Kitaoka H, Kubo T, Hayashi K, Yamasaki N, Matsumura Y, Furuno T, Doi YL: Tissue Doppler imaging and prognosis in asymptomatic or mildly symptomatic patients with hypertrophic cardiomyopathy. Eur Heart J Cardiovasc Imaging 2013, 14:544-549.

doi:10.1186/1471-2261-14-194

Cite this article as: Ma et al:: Left ventricular filling pressure assessed by exercise TDI was correlated with early HFNEF in patients with nonobstructive hypertrophic cardiomyopathy. BMC Cardiovascular Disorders 2014 14:194.

\section{Submit your next manuscript to BioMed Central and take full advantage of:}

- Convenient online submission

- Thorough peer review

- No space constraints or color figure charges

- Immediate publication on acceptance

- Inclusion in PubMed, CAS, Scopus and Google Scholar

- Research which is freely available for redistribution 